\title{
Pyrolysis and Gasification of I ndustrial Waste Towards Substitution Fuels Valorisation
}

\section{C.G. J ung}

Industrial waste is usually sorted in order to valorise most of minerals, polymers and metals. This sorting does generate a sorting residue with a rather high calorific value. The present study shows the opportunities of producing gaseous or liquid substitution fuels by pyrolysis or gasification of industrial sorting residues. By the use of the predictive model, it is possible to evaluate, for various inputs (tyres, fluffs, mixed plastics and biomass residues), the mass en energy balance for each of these thermal treatments.

Opportunities to produce substitution fuels issued from these waste streams are evaluated.

CEB Working Paper $N^{\circ}$ 09/001

2009

Université Libre de Bruxelles - Solvay Brussels School of Economics and Management Centre Emile Bernheim

ULB CP145/01 50, avenue F.D. Roosevelt 1050 Brussels BELGIUM

e-mail: ceb@admin.ulb.ac.be Tel. : +32 (0)2/650.48.64 Fax : +32 (0)2/650.41.88 


\title{
Pyrolysis and Gasification of Industrial Waste Towards Substitution Fuels Valorisation
}

\author{
C.Gisèle Jung ${ }^{*}, \mathrm{PhD}$. \\ Université Libre de Bruxelles (ULB) - Solvay Business School - Centre Emile Bernheim \\ Faculté des Sciences Appliquées - Matières et Matériaux
}

(Received september 2008)

\begin{abstract}
Industrial waste is usually sorted in order to valorise most of minerals, polymers and metals. This sorting does generate a sorting residue with a rather high calorific value. The present study shows the opportunities of producing gaseous or liquid substitution fuels by pyrolysis or gasification of industrial sorting residues. By the use of the predictive model, it is possible to evaluate, for various inputs (tyres, fluffs, mixed plastics and biomass residues), the mass en energy balance for each of these thermal treatments.

Opportunities to produce substitution fuels issued from these waste streams are evaluated.
\end{abstract}

\section{INTRODUCTION}

Nowadays, it is of major importance to develop alternative energy production paths. Next to classical nuclear, hydroelectric, wind, solar, geothermic .ways, there is also an increasing interest in the production of substitution fuels in order to decrease the fossil fuel dependence.

Biofuels is not the only alternative for the production of substitution fuels according to the fact that biosphere is an important resource for the production of food for human. If we do not want to repeat the sad experience of the growth of metallurgy with the use if biosphere in the Middle Age in the 18 th century, and insure a certain energetic future, it is essential to give priority to the development of biofuel's production paths from waste.

A first example comes from the urban community of Lille where sewage sludge are used in biomethanisation in order to produce a gaseous fuel used by the urban buses.

It is possible to gasify waste from the forest exploitation as it is performed in Austria, with the production of biodiesel which insure urban heating ${ }^{\dagger}$.

Waste from agricultural-food and residues form forest exploitation can be treated and enter the alcohol route.

Finally, other routes could be explored, i.e. the one of plastic waste or used tyres, that, if recycling is not possible, could be pyrolysed or gasified in order to generate substitution fuels.

Industrial waste is usually sorted in order to valorise most of minerals, polymers and metals. This sorting does generate a sorting residue with a rather high calorific value.

The present study shows the opportunities of producing gaseous or liquid substitution fuels by pyrolysis or gasification of industrial sorting residues, industrial waste including food industry as well as wood and forest residues.

\section{EXPERIMENTAL}

\subsection{Predictive model}

We have developed a predictive model /1/ based on the behaviour of a mixed material during a thermal treatment.

\footnotetext{
*Phone: +32 26503051 Fax: + 3226504873 Email: cgjung@ulb.ac.be

${ }^{\dagger}$ I.e. Güssing gasifier in Austria.
} 
In ASTM norms for the volatile matter determination, the working conditions are close to pyrolysis conditions but are at higher temperature $\left(800^{\circ} \mathrm{C}\right)$ than pyrolysis (around $500^{\circ} \mathrm{C}$ ). Therefore, TGA analysis in inert atmosphere gives the carbonisation yield and the shift from the ASTM norm for volatile matter determination

Therefore, the predictive model is based on hypothesis on the behaviour of the volatile matter during thermal treatment.

Each fraction of the mixture has to be characterised by its proximate analysis in order to estimate the mass balances. The elemental analysis $(\mathrm{C}, \mathrm{H}, \mathrm{O})$ and $\mathrm{NCV}$ of each fraction are needed to estimate the energy balance.

Taking into account the proximate analysis of the input material (water content $\mathrm{W}$, volatile matter $\mathrm{VM}^{*}$ and ashes content $\left.\mathrm{A}^{*}\right)$, it is possible to estimate the fixed carbon:

$\mathrm{C}_{\mathrm{F}}=100-\mathrm{VM}-\mathrm{A}$ and $\mathrm{C}_{\mathrm{F}} *=100-\mathrm{VM}^{*}-\mathrm{A}^{*}$ with * meaning on dry matter $\mathrm{M}=100-\mathrm{W}$ Assuming that, during slow carbonization, the volatile matter is oriented with the water in the gas phase and that the fixed carbon is recuperated in the solid phase with the ashes, the mass balance is estimated:

Mass of gas phase: $\quad \mathrm{M}_{\mathrm{G}}=\alpha \cdot \mathrm{VM}+\mathrm{W}$ with $\quad \mathrm{VM}=\mathrm{VM}^{*} \cdot \frac{\mathrm{DM}}{100}$

Mass of solid phase (char): $M_{S}=C_{F}+A+(1-\alpha) V M \quad$ with $A=A^{*} \cdot \frac{D M}{100}$

It is assumed that the carbon content $\left(\mathrm{C}_{\mathrm{VM}}\right)$ and the hydrogen content $\left(\mathrm{H}_{\mathrm{VM}}\right)$ of the volatile matter (VM) are the following:

$\mathrm{C}_{\mathrm{VM}}=\mathrm{C}_{\mathrm{DM}}-\mathrm{C}_{\mathrm{F}}$ and $\mathrm{H}_{\mathrm{VM}}=\mathrm{H}_{\mathrm{DM}}$

The net calorific value of the volatile matter is estimated in the pyrolytic gases based on the use of combustion heat values of light hydrocarbons as $\mathrm{NCV}_{\mathrm{VM}}=\mathrm{f}\left(\mathrm{C}_{\mathrm{VM}}, \mathrm{H}_{\mathrm{VM}}, \mathrm{O}_{\mathrm{VM}}\right)$.

On the other hand, the hypothesis for the evaluation of the char requires the experimental value of $\alpha$ obtained by TGA measurements.

The volatile matter remaining in the char is then: $\mathrm{VM}_{\text {char }}=(1-\alpha)$. VM.

Subsequently, the fixed carbon in the char will be evaluated: $\mathrm{C}_{\mathrm{F}}+\mathrm{VM}_{\mathrm{char}}+\mathrm{A}$.

Finally, the net calorific value of the char is estimated by the sum of ponderated values of the NCV of the carbon and the volatile matter in the char:

$\mathrm{NCV}_{\text {char }}=\% \mathrm{C}_{\text {Char }} \cdot \mathrm{NCV}_{\mathrm{C}}+\% \mathrm{VM}_{\mathrm{Char}} \cdot \mathrm{NCV}_{\mathrm{VM}}$

In summary, the predictive model estimates the solid and gas yields during pyrolysis of the waste mixture and also the net calorific value of the char and the gases by assuming the additivity of the results for each fraction at the tempereature estimated by the TGA analysis (generally between 450 and $550^{\circ} \mathrm{C}$ ).

In the case of slow pyrolysis, the yield of products issued of the process is depending on temperature, residence time and heat transfer. In this model, the carbonisation yield $(\alpha \leq 1)$ characterises the pyrolysis efficiency.

For gasification, the amount of gaz and its calorific value is evaluated assuming that the char issued from the first carbonisation stage $(\alpha=1)$ is oxidized in $\mathrm{CO}$, in a second stage, using a defect of air based on the amount of carbon contained in this specific amount of char..

\subsection{Lab scale and pilot scale facilities}

The results issued from the predictive model can be compared to results issued from lab-scale experience and those issued from the scaling up in pilot plant installations using different types of technologies. 
- Lab scale instrumentation (ULB)

A small rotating cage (volume:11) is filled to three quaters of its capacity and heated electrically under inert atmosphere of nitrogen $\left(10^{\circ} \mathrm{C} / \mathrm{min}\right)$ up to $550^{\circ} \mathrm{C}$ and remaining at this final temperature for half a hour. The sample has a mass between 50 to $250 \mathrm{~g}$ (depending on its specific mass). The solid and the condensed gas are collected and waited. The non-condensable gas is evaluated by difference.

- CUTEC (D) $(30 \mathrm{~kg} / \mathrm{h})$ and THIDE (F) rotary kilns $(500 \mathrm{~kg} / \mathrm{h})$ are pilote scale facilities has been used for runs with plastic sorting residues and other waste materials collecting the different pyrolytic products.

- TRAIDEC was an electrically heated pilot belt kiln $(0,5 \mathrm{t} / \mathrm{h})$ that had made runs for used tyres pyrolysis.

\section{MATERIALS}

Tyres and different types of waste residues, industrial fluffs (Table 1), a mixed plastics fraction (Tables 2 and 3) as residue of a sorting plant as well as biomass residues (Table 4) have been studied. An example of the plastic fraction of the residue issued from a sorting plant is used as example and the composition is presented in Table 2. The characteristics of some of the polymers and of the mixture are presented in Table 3.

Table 1. Waste characteristics for tyres and 3 types of fluffs.

\begin{tabular}{|c|c|c|c|c|}
\hline & Tyre & Fluff 1 & Fluff 2 & Fluff 3 \\
\hline Dry Matter \% & 97 & 90 & 89 & 63 \\
\hline Ash content $\% *$ & 23.8 & 5 & 20 & 13 \\
\hline Volatile Matter\%* & 51.3 & 87.8 & 48.2 & 71.5 \\
\hline Carbon $\% *$ & 67.3 & 52 & 50 & 52 \\
\hline Hydrogen $\% *$ & 4.4 & 8 & 6 & 9 \\
\hline $\mathrm{NCV} \mathrm{MJ} / \mathrm{kg}$ & 25.0 & 20.6 & 18 & 15 \\
\hline $\begin{array}{l}\text { Including } 150 \mathrm{~kg} / \mathrm{t} \\
* \text { : on dry basis }\end{array}$ & steel & & & \\
\hline
\end{tabular}

Table 2: Mixed polymers composition

\begin{tabular}{ccccccc}
\hline $\boldsymbol{L P D E}$ & $\boldsymbol{H P D E}$ & $\boldsymbol{P S}$ & $\boldsymbol{P U}$ & $\boldsymbol{P V C}$ & $\boldsymbol{P E T}$ & $\boldsymbol{P P}$ \\
$10 \%$ & $10 \%$ & $20 \%$ & $10 \%$ & $10 \%$ & $20 \%$ & $20 \%$ \\
\hline
\end{tabular}

Table 3. Characteristics of individual polymers and mix of Table 2.

\begin{tabular}{lllll}
\hline & LPDE & $\boldsymbol{P U}$ & $\boldsymbol{P V C}$ & MIX Table 2 \\
\hline Dry Matter \% & 100 & 100 & 100 & 100 \\
Ash content\%* & 0.1 & 4.4 & 2.1 & 0.9 \\
Volatile Matter\%* & 99.9 & 95.6 & 93.1 & 98.5 \\
Carbon\%* & 85.7 & 63.1 & 45.0 & 75.8 \\
Hydrogen \%* & 14.2 & 6.3 & 5.6 & 9.3 \\
NCV MJ/kg & 43.0 & 25.7 & 20.0 & 34.0 \\
\hline
\end{tabular}


Table 4: Characteristics for biomass residues.

\begin{tabular}{lc|c}
\hline & Olive tree pruning & Sunfower \\
\cline { 1 - 3 } Dry Matter \% & 95 & 94 \\
Ash content\%* & 0.2 & 10.3 \\
Volatile Matter\%* & 99.4 & 70.5 \\
Carbon/DM\%* & 47.3 & 42.4 \\
Hydrogen/DM \%* & 6.4 & 5.9 \\
NCV MJ/kg & 19.0 & 16.9 \\
$\quad *$ : on dry basis & & \\
\hline
\end{tabular}

\section{RESULTS AND DISCUSSION}

Material has been studied using the predictive model (described in $\$ 2 b$ ) for pyrolysis and gasification and the results are presented in Tables 5 to 10 .

Table 5. Results issued from the predictive model for pyrolysis for tyres and 3 types of fluffs.

\begin{tabular}{|c|c|c|c|c|}
\hline & Tyre & Fluff 1 & Fluff 2 & Fluff 3 \\
\hline \multicolumn{5}{|l|}{ CHAR } \\
\hline $\mathrm{Kg} / \mathrm{t}$ & 317 & 110 & 461 & 180 \\
\hline $\mathrm{NCV} \mathrm{MJ} / \mathrm{kg}$ & 25.6 & 19.4 & 20.1 & 17.8 \\
\hline Ash $\%$ & 21.0 & 41 & 38.6 & 45.6 \\
\hline \multicolumn{5}{|l|}{ GAS } \\
\hline $\mathrm{Kg} / \mathrm{t}$ & 513 & 890 & 539 & 820 \\
\hline NCV MJ/kg & 36.1 & 22.1 & 14.7 & 14.1 \\
\hline \multicolumn{5}{|l|}{ Steel } \\
\hline $\mathrm{kg} / \mathrm{t}$ & 150 & & & \\
\hline *: on dry basis & & & & \\
\hline
\end{tabular}

Table 6. Results issued from the predictive model for gasification for tyres and 3 types of fluffs.

\begin{tabular}{|c|c|c|c|c|c|}
\hline & & Tyre & Fluff 1 & Fluff 2 & Fluff 3 \\
\hline \multicolumn{6}{|l|}{ GAS } \\
\hline & $\mathrm{Kg} / \mathrm{t}$ & 1645 & 1332 & 2463 & 1399 \\
\hline & $\mathrm{NCV} \mathrm{MJ} / \mathrm{kg}$ & 28.1 & 22.6 & 21.8 & 18.7 \\
\hline Ashes & $\mathrm{kg} / \mathrm{t}$ & 238 & 50 & 200 & 130 \\
\hline
\end{tabular}

For used tyres, proximate analysis gives $23.8 \%$ ashes and $51.3 \% \mathrm{VM}$ (Table 2). There should be $24.9 \%$ fixed carbon. Using the model, slow pyrolysis of used tyres leads to about $317 \mathrm{~kg} / \mathrm{t} \mathrm{char}$ $(21 \%$ ashes, $25.6 \mathrm{MJ} / \mathrm{kg}), 150 \mathrm{~kg} / \mathrm{t}$ steel and $513 \mathrm{~kg} / \mathrm{t}$ of gas $(36.1 \mathrm{MJ} / \mathrm{kg})$ at $100 \%$ carbonization $(. \alpha=1)$ If we consider the tyre as a multi component system, the application of the model could take into account different carbonization yields for each component according their behaviour in the furnace and give a higher amount of char (including some volatile matter).

Pilot scale pyrolysis runs at TRAIDEC (F) for tyres at $550^{\circ} \mathrm{C}$ gives $550 \mathrm{~kg}$ of gas, and $450 \mathrm{~kg}$ of char with $150 \mathrm{~kg}$ of steel assuming a total carbonisation in their furnace.

For fluffs, pyrolysis leads to very char with a poor quality having a high ash content (Table 5). Nevertheless, gasification is an interesting way of valorisation according to the fact that there could be less solid residues according to the composition (Table 1 and Table 6). 
The predictive model is applied for mixed plastics according the composition given in Table 1. The same approach presented is used with $100 \%$ carbonisation $(\alpha=1)$

Table 7 Results issued from the predictive model for pyrolysis of polymers and mix of Table 4

\begin{tabular}{|c|c|c|c|c|}
\hline & $\angle P D E$ & $\boldsymbol{P U}$ & $P V C$ & MIX Table 4 \\
\hline \multicolumn{5}{|l|}{ CHAR } \\
\hline $\mathrm{Kg} / \mathrm{t}$ & 1 & 44 & 69 & 15 \\
\hline NCV MJ/kg & 0 & 0 & 23.0 & 11.7 \\
\hline VM \% & 0 & 0 & 0 & 0 \\
\hline Ash $\%$ & 100 & 100 & 30.0 & 64.2 \\
\hline \multicolumn{5}{|l|}{ GAS } \\
\hline $\mathrm{Kg} / \mathrm{t}$ & 999 & 956 & 931.0 & 985 \\
\hline $\begin{array}{r}\mathrm{NCV} \mathrm{MJ/kg} \\
* \text { : on dry basis }\end{array}$ & 43.0 & 26.9 & 19.9 & 34.4 \\
\hline
\end{tabular}

Table 8. Results issued from the predictive model for gasification of polymers and mix of Table 2.

$\begin{array}{llll}L P D E & P U & \text { PVC } & \text { MIX Table } 3\end{array}$

GAS

$\begin{array}{rllll}\mathrm{Kg} / \mathrm{t} & 1000 & 956 & 1267 & 1022 \\ \mathrm{NCV} \mathrm{MJ} / \mathrm{kg} & 43.0 & 26.9 & 20.9 & 34.0 \\ \mathrm{~kg} / \mathrm{t} & 1 & 44 & 20.6 & 9\end{array}$

For mixed plastics residues, both pyrolysis and gasification could be interesting ways of valorisation depending on the potential end users of the different substitution fuels $/ 2-4 /$. The interest for this type of mixtures is the same quantities of char produced by pyrolysis and the quite high value of the hot pyrolytic gas (Table 7) which has to be used on site to avoid the formation by condensation.

Taking into account that presently only $30 \%$ of plastic waste is recycled and the remaining being landfilled or incinerated; there is a real opportunity to process these used plastics in order to produce alternative fuels $/ 2 /$.

Pyrolysis and gasification could also be useful to valorise biomass residues and produce alternative fuels. Examples of the use of the predictive model are shown hereafter in Table 9 for pyrolysis using two different carbonisation yields and for gasification (Table 10).

Table 9: Application of the model for biomass residues by pyrolysis

\begin{tabular}{|c|c|c|c|c|}
\hline & \multicolumn{2}{|c|}{ Olive tree pruning } & \multicolumn{2}{|c|}{ Sunfower } \\
\hline & $\alpha=1$ & $\alpha=0.75$ & $\alpha=1$ & $\alpha=0.75$ \\
\hline \multicolumn{5}{|l|}{ CHAR } \\
\hline $\mathrm{Kg} / \mathrm{t}$ & 6 & 243 & 276 & 441 \\
\hline NCV MJ/kg & 22.2 & 22.1 & 21.4 & 19.9 \\
\hline Ash $\%$ & 32.3 & 0.8 & 34.8 & 21.8 \\
\hline VM\% & 0 & 97.6 & 0 & 37.4 \\
\hline \multicolumn{5}{|l|}{ GAS } \\
\hline $\mathrm{Kg} / \mathrm{t}$ & 994 & 757 & 625 & 559 \\
\hline $\mathrm{NCV} \mathrm{MJ} / \mathrm{kg}$ & 21.0 & 20.7 & 35.8 & 15.4 \\
\hline VM\% & 95.4 & 93.9 & 91.3 & 88.7 \\
\hline
\end{tabular}


Table 10: Application of the model for several biomass residues by gasification

\begin{tabular}{lrc|c}
\hline & & Olive tree pruning & Sunflower \\
\hline GAS & & & \\
& $\mathrm{Kg} / \mathrm{t}$ & 1022 & 1965 \\
& $\mathrm{NCV} \mathrm{MJ} / \mathrm{kg}$ & 21.1 & 20.6 \\
Ashes & $\mathrm{kg} / \mathrm{t}$ & 2 & 103 \\
\hline
\end{tabular}

* on dry basis

For biomass residues, it is important to insure experimentally a total carbonisation (good heat transfer by mixing and sufficient long residence time up to one hour) of the biomass in order to minimize solid residues (Table 9: down to $6 \mathrm{~kg} / \mathrm{t}$ for olive tree pruning). These results show that at a temperature around $500^{\circ} \mathrm{C}$, it is possible to reach more than $90 \%$ gas efficiency by pyrolysis. This has been frequently proved experimentally /5-8/. The NCV of gaseous end products are higher by pyrolysis than by gasification but in some cases pyrolytic char quantities are larger and difficult to valorise (Table 9 and Table 10).

Experimental laboratory tests for the biomass residues are under development at Aristotle University of Thessalonique /9/.

\section{CONCLUSION}

The end product characteristics are quite different for pyrolysis and gasification so that the application fields will have to be selected in order to select the process according to the local constraints $/ 10 /$.

Experimental pilot runs are needed in order to validate these results and for tracing the eventual pollutants. For several waste, the results using the model has already been validated by pilot runs $/ 11 /$.

The predictive model used in this study is an easy scientific decision tool, helping in making the right choice for thermal treatment in the production of substitution fuels in relation with input and the local constraints.

In consequence, this work enhances the efficiency in waste management for sustainable development including the decrease of the energy dependence in EU.

\section{ACKNOWLEDGMENT}

We thank Hon. Prof. A.Fontana for initiating the development of the predictive model for waste treatments based on proximate analysis.

\section{REFERENCES}

1. C.G. Jung, E. de Belder and A.Fontana, $16^{\text {th }}$ International Symposium on Analytical and Applied Pyrolysis - Pyrolysis 2004, Alicante, Spain (2004).

2. C.G. Jung and A.Fontana, Production of Gaseous and Liquid fuels by Pyrolysis and Gasification of Plastics: Technological Approach, in Feedstock Recycling and Pyrolysis of Waste Plastics edited by John Scheirs and Walter Kaminsky, Wiley, New York, 251-283 (2006).

3. C.G.Jung, and A.Fontana, 1st International Conference on Engineering for Waste Treatment, WasteEng05, Albi, France, (May 17-19, 2005). 
4. C.G.Jung, and A.Fontana, $17^{\text {th }}$ International Symposium on Analytical and Applied Pyrolysis Pyrolysis 2006, Budapest. (2006).

5. A.V. Bridgwater, Progress in Thermochemical Biomass Conversion, Wiley-Blackwell, London, (2001).

6. A.V. Bridgwater, S.Czernik and J. Diebold, Fast Pyrolysis of Biomass: A Handbook, CPL Press, Newsbury, Berks RG19 3UP, UK (2008).

7. A.V. Bridgwater, Advances in Thermochemical Biomass Conversion, 1, Springer, Heidelberg, (2008).

8. C.G. Jung, Pyrolysis Network meeting - PyNe, Bruges, April (2004).

9. A.Zabaniotou and V. Skoulou, Thermal Science, 11,(3), 125-134 (2007).

10. A.V.Bridgwater and G.V.C.Peacocke, Fast pyrolysis processes for biomass. Renewable and Sustainable, Energy Reviews, 4, 1-73 (2000).

11. C. G. Jung, O. Ioannidou and A. Zabaniotou, $18^{\text {th }}$ International Symposium on Analytical and Applied Pyrolysis - Pyrolysis 2008, Patras. (2008).' 